\title{
Investigating Iraqi EFL College Students’ Ability of Parametric Resetting
}

\author{
Mahdi I. Kareem al-Utbi*, Mawj K. Obeid Aljubory \\ Department of English, College of Languages, University of Baghdad, Iraq \\ Corresponding Author: Mahdi I. Kareem al-Utbi, E-mail: mik_alutbi@colang.uobaghdad.edu.iq
}

\section{ARTICLE INFO}

Article history

Received: December 11, 2017

Accepted: January 25, 2018

Published: April 30, 2018

Volume: 9 Issue: 2

Advance access: March 2018

Conflicts of interest: None

Funding: None

Key words:

Arabic,

English,

Iraqi EFL,

Parameters,

Resetting

\begin{abstract}
This paper tries to answer whether Iraqi EFL college students are able to reset the parametric values of their native Arabic into those which suit English. It aims at enhancing Iraqi students' knowledge of some of the parametric values of English via tackling three parameters: Nullsubject parameter, Head-parameter, and Serial parameter. To achieve the aim of this study, Grammaticality Judgment Tasks are administered to sixty students of the fourth year at the Department of English- College of Languages/University of Baghdad for the academic year 2016-2017. The students' responses have been corrected and statically analysed. The study concludes that Iraqi EFL students' ability to reset parameters varies as to the parameter in question since they have succeeded to reset the Head parameter, but failed to reset the Serial parameter; this is accompanied by a partial ability to rest the Null-subject parameter. As well, it has further been revealed that Iraqi EFL students' inability to reset a parameter is due to negative transfer from Arabic to English, hence EFL learners need be exposed to extensive input data to encourage the resetting of parameters.
\end{abstract}

\section{INTRODUCTION}

Historically, principles and parameters theory (henceforth PPT), originated in Chomsky (1981), has been a productive research program in the history of generative grammar. That is, in the nineteenth century the relationships between languages and groups of languages have been mainly described in terms of a common ancestry. By contrast, PPT is concerned with a theory of grammar that is applicable for all human languages. In other words, the grammar in such a theory is postulated to be an innate component of the human mind, hence it establishes the relationship between all languages, not only those that are related by common ancestry (Freidin, 2007:1).

Furthermore, one of the main objectives of PPT is to provide an explanation for the logical problem of language acquisition. That is, how children come to have a complex grammatical knowledge that goes beyond the input commonly identified in their linguistic environment. In this instance, Chomsky postulates the existence of Universal Grammar (henceforth UG). The question is then: where does such an abstract notion like UG come from? Chomsky believes that human beings are endowed with an innate language faculty that incorporates a theory of UG; UG in turn consists of a set of universal principles supported by a set of universal parameters. The principles are wired into the language faculty, hence they are available to all speakers, while the parameters have binary values, and each language sets the parameters to a value specific to itself (Cook and Newson, 1994:143).

In addition, Chomsky's PPT plays a central role in the process of first language acquisition in the sense that the universal principles are innately endowed and so need not be learned by children. The child's task then is limited to reset the parameters to the values appropriate to his language.

PPT also plays a role in SLA, but the main argument is whether L2 learners are capable to reset the parameters from the L1 values to the L2 values. Some argue that L2 grammar will only be limited to the L1 parameter values; others argue that learners will reset the L1 values to the L2 when these are unable to cope with the L2 input; still others, however, argue that learners fluctuate between the L1 and L2 settings but ultimately are capable to reset parameters to the $\mathrm{L} 2$ values (White, 2003).

In this paper, the researchers attempt to answer the following:

i- $\quad$ Are Iraqi EFL college students able to reset those parametric variations from their values in Arabic, as their L1, into English, their L2?

ii- Do Iraqi EFL college students resort to strange structures, i.e. not found neither in L1 nor in L2, in the process of parametric resetting? 
iii- Are Iraqi EFL college students aware, in the first place, of the parametric variation between L1 and L2?

iv- Does negative transfer play a role in the resetting process?

In order to answer these questions, an investigation is made of three parameters, viz. Null-subject parameter, Head-parameter, and Serial parameter. By so doing, they aim at exposing a number of parametric variations between the two languages, as well as enhancing Iraqi EFL college students' knowledge of the named parameters and the way they vary. And, for such an aim, Grammaticality Judgment Tasks (GJTs, henceforth) are adopted as a tool for the investigation in hand. As such, GJTs are administered among 60 Iraqi EFL Fourth-Year college students, Department of English, College of Languages- University of Baghdad for the academic year 2016-2017.

\section{PARAMETRIC VARIATIONS BETWEEN ENGLISH AND ARABIC}

\section{Null-subject Parameter}

Languages are classified cross-linguistically as to whether they allow the subjects to be overt or covert in a clause. That is, languages that do not allow the subjects to be null are called Non-null subject languages, while languages that allow null subjects are called Null-subject languages. English is a typical non-null subject language: English sentences always require subjects in front of the verb in order to be grammatical, as in:

1- John understood the question.

Where 'John' is the subject of the verb 'understand' This shows that modern English must have an overt subject whether nominal or pronominal in every finite clause (Radford, 2004:27). Arabic is a null-subject language, and moreover, such a subject can be nominal or pronominal. However, when the subject is pronominal, it can be either covert or overt as in:

2- قر أتِ الكتابَ [Qara'ti lkitaaba] (Read-past-she-. The book. Acc.)

3- امنت، باله 'Aamantu billaah] (Believe-Past-I-Nom in-Allah. Gen.)

In (2), the subject is a covert pronoun and is understood as " هي " [hiya] "she" which is a third person feminine singular pronoun acting as a covert subject in Arabic, but in (3) the subject is an overt pronoun which is the nominative suffix “乌ُ [tu] "I" at the end of the verb (al-Taahir, 2002:48).

\section{Head-parameter}

This parameter is concerned with the position of heads in a language. English is a head-initial language where the head of the phrase precedes its complement, regardless of whether the phrase is a VP, NP, PP, (Kreidler, 2001:148) as in:

4- Drew an elephant

5- Education for life

6- In the car.

Arabic, here, works identically in that heads found also initial in the phrase. Furthermore, head and complement must be identical in person, number, gender, and (in)definiteness as in (Khalaf, 1994:195):

7- 'هذا منزل، ضيق ' [hatha manzilun dhayiqun] (This house. Nom narrow.Nom) "This is a narrow house"

8- دلت، حديقةً جميلةً 'dakhaltu hadeeqatan jameelatan] (enter-Past-I-Nom. garden. Acc. beautiful. Acc) "I entered a beautiful garden".

\section{Serial Parameter}

A serial verb construction (henceforth SVC) refers to a grammatical structure in which two or more verbs appear together without a marker of coordination or subordination (Iwasaki and Ingkaphiron 2005:231). English is not a serial verb language; it allows only one finite verb in each clause (Comrie and Corbett, 2005:87). Thus, an English sentence such as in: 9- *I went eat lunch.

is ungrammatical because the verb 'eat' is non-finite and needs to be preceded by the infinitive 'to', so as to form the sentence in (10) below (Iwasaki and Ingkaphiron, 2005:231):

10- I went to eat lunch.

By contrast, Arabic is a serial verb language since it allows two or more finite verbs to occur together in a clause (Karimi et.al., 2007:43). Consider for instance:

11- جلسَتْ فاطمةُ ترسم 2jalasat Fatimatu tarsimu] (sit-Past-she Fatimatu-Nom. Draw-Present-Nom) "Fatima sat to draw"

In (11) two finite verbs جلسَت [jalasat] and ترسم[tarsimu] come together without any conjunction.

\section{DATA ANALYSIS}

\section{The Null - Subject Parameter}

The study has demonstrated students' inability in resetting this parameter on the recognition level since they were enjoying both settings at the same time; the -null subject and +null subject values. Students consider sentence such as 'suddenly, jumped from the window' as correct in much the same way as 'Bill plays football every Friday', the following Table 1 and Figure 1 show students' performance on the recognition level:

On the production level, the students have shown a rather different behaviour. Students especially in the translation part exhibited a successful resetting of this parameter from its +null subject value in Arabic to its -null subject value in English, thus a sentence such as كتبا الدرس معا (T1 S,3) is correctly translated into 'They wrote the lesson together'. The following Table 2 and Figure 2 display students' performance on the production level:

On part three (correction task), the students were unable to correct the sentences that lacked overt subjects, so a sentence such as 'Each morning, eats breakfast at eight o'clock' (T3 S,4) was corrected by either putting the adverb after the noun, or by adding a modal verb thus rendering sentences such as 'eat breakfast each morning at eight o'clock', 'Each morning, should eat breakfast at eight o'clock'. However, such a sentence needs only an overt subject to be grammatically correct as in 'Each morning, he eats breakfast at eight 
Table 1. The frequency of resetting the null- subject parameter on the recognitionl level

\begin{tabular}{|c|c|c|c|c|c|}
\hline \multicolumn{2}{|c|}{ Correct responses } & \multicolumn{2}{|c|}{ Incorrect responses } & \multicolumn{2}{|c|}{ Avoided sentences } \\
\hline Frequency & Percentage & Frequency & percentage & Frequency & Percentage \\
\hline 107 & $44.58 \%$ & 121 & $50.41 \%$ & 12 & $5 \%$ \\
\hline
\end{tabular}

Table 2. The frequency of resetting the null-subject parameter on the production level: translation task

\begin{tabular}{|c|c|c|c|c|c|}
\hline \multicolumn{2}{|c|}{ Correct responses } & \multicolumn{2}{|c|}{ Incorrect responses } & \multicolumn{2}{|c|}{ Avoided sentences } \\
\hline Frequency & Percentage & Frequency & Percentage & Frequency & Percentage \\
\hline 179 & $74.58 \%$ & 49 & $20.41 \%$ & 12 & $5 \%$ \\
\hline
\end{tabular}

Table 3. The frequency of resetting the null subject parameter on the production level: correction part

\begin{tabular}{|c|c|c|c|c|c|}
\hline \multicolumn{2}{|c|}{ Correct responses } & \multicolumn{2}{|c|}{ Incorrect responses } & \multicolumn{2}{|c|}{ Avoided sentences } \\
\hline Frequency & Percentage & Frequency & percentage & Frequency & Percentage \\
\hline 83 & $34.58 \%$ & 101 & $48.75 \%$ & 40 & $16.66 \%$ \\
\hline
\end{tabular}

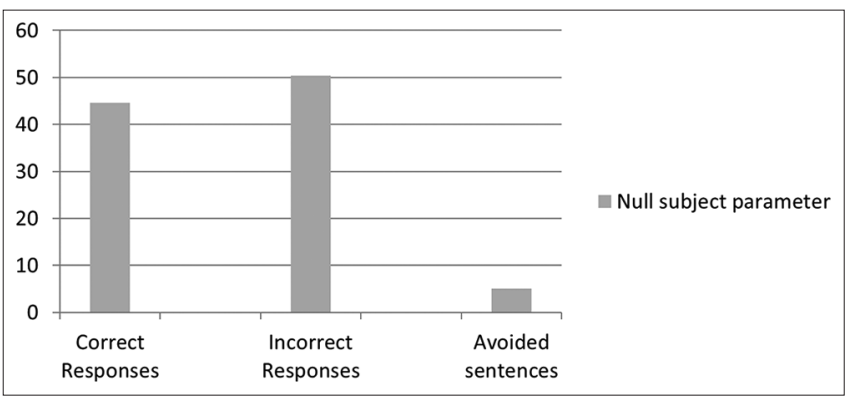

Figure 1. The frequency of resetting the null-subject parameter on the recognition level

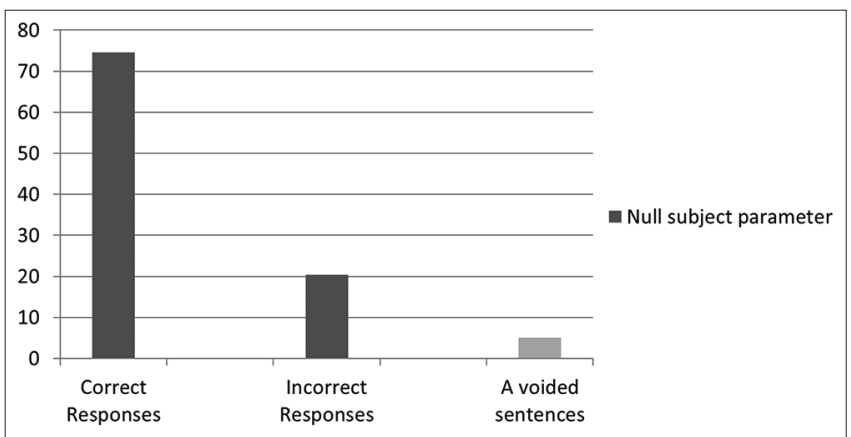

Figure 2. The frequency of resetting the null subject parameter on the production level: translation task

o'clock'. The following Table 3 and Figure 3 show students' performance on the production level:

\section{The Serial Parameter}

Statistics shows that the students were unable to reset this parameter on the recognition level. They correctly accepted the grammatical sentences, but, unfortunately, along with the ungrammatical ones because they were entertaining more than one value of the parameter at a time. This resulted in the failure to rest this parameter since each parameter allow would only one value. The frequency of resetting the Serial parameter is shown in the following Table 4 and Figure 4.
On the production level (the translation part), the students exhibited the same failure in resetting this parameter. That is, when encountering Arabic sentences that have more than one finite verb, they would translate these sentences in much the same way they written in Arabic, thus a sentence such as تجلس فاطمة الان ترسم اللوحة/tajlisu Fatimatu alaan tarsimu/is wrongly translated into 'Fatima is sitting and painting' or ' Fatima is sitting now and painting. However, the accurate translation of this sentence is " Fatima is sitting to draw the painting now'

Table (5) and Figure (5) expose students' performance frequency on the production level: translation part. The correction task proved that the students were unable to correct the sentences that included two verbs. This lead them to correct the sentences according to different grammatical rules. Thus, a sentence that had two finite verbs such as ' He watched her played tennis' is wrongly corrected into 'He watched her plays tennis'. Students could correct this sentence by adding the present participle -ing to the verb ' play', thus rendering a sentence such as 'He watched her playing tennis' which is grammatically correct. The frequency of resetting the serial parameter in this task is explained by the following Table 6 and Figure 6 .

\section{Head- Parameter}

Students have shown a successful resetting of this parameter on both levels. Statistics shows that a higher percentage of students have considered sentences such as John bought a new beautiful house as correct, and refused sentences such as Mary wants to buy white flower beautiful. The accurate percentage of students' performance is shown in the following Table 7 and Figure 7.

The production level shows no significant variability. That is, on the translation task students have also shown a successful resetting of this parameter, thus a sentence such as أنتريت، فستاناً جميلاً translated into (I bought a beautiful dress).

Table (8) and Figure (8) clearly show frequency of their performance at this level. On the correction task, the 
Table 4. The frequency of resetting the serial parameter on the recognition level

\begin{tabular}{lccccccc}
\hline Correct responses & & & \multicolumn{2}{c}{ Incorrect responses } & & \multicolumn{2}{c}{ Avoided sentences } \\
\cline { 1 - 2 } Frequency & Percentage & & Frequency & percentage & & Frequency & Percentage \\
\hline 150 & $32.5 \%$ & 78 & $62.5 \%$ & $5 \%$ & 12 & 50 \\
\hline
\end{tabular}

Table 5. The frequency of resetting the serial parameter on the production level: translation task

\begin{tabular}{|c|c|c|c|c|c|}
\hline \multicolumn{2}{|c|}{ Correct responses } & \multicolumn{2}{|c|}{ Incorrect responses } & \multicolumn{2}{|c|}{ Avoided sentences } \\
\hline Frequency & Percentage & Frequency & percentage & Frequency & Percentage \\
\hline 90 & $37.5 \%$ & 138 & $57.5 \%$ & 12 & $5 \%$ \\
\hline
\end{tabular}

Table 6. The frequency of resetting the serial parameter on the production level: correction task

\begin{tabular}{|c|c|c|c|c|c|}
\hline \multicolumn{2}{|c|}{ Correct responses } & \multicolumn{2}{|c|}{ Incorrect responses } & \multicolumn{2}{|c|}{ Avoided sentences } \\
\hline Frequency & Percentage & Frequency & Percentage & Frequency & Percentage \\
\hline 79 & 32.91 & 121 & 50.42 & 40 & 16.66 \\
\hline
\end{tabular}

Table 7. The frequency of resetting the head-parameter on the recognition level

\begin{tabular}{|c|c|c|c|c|c|}
\hline \multicolumn{2}{|c|}{ Correct responses } & \multicolumn{2}{|c|}{ Incorrect responses } & \multicolumn{2}{|c|}{ Avoided sentences } \\
\hline Frequency & Percentage & Frequency & Percentage & Frequency & Percentage \\
\hline 170 & $70.83 \%$ & 58 & $24.16 \%$ & 12 & $5 \%$ \\
\hline
\end{tabular}

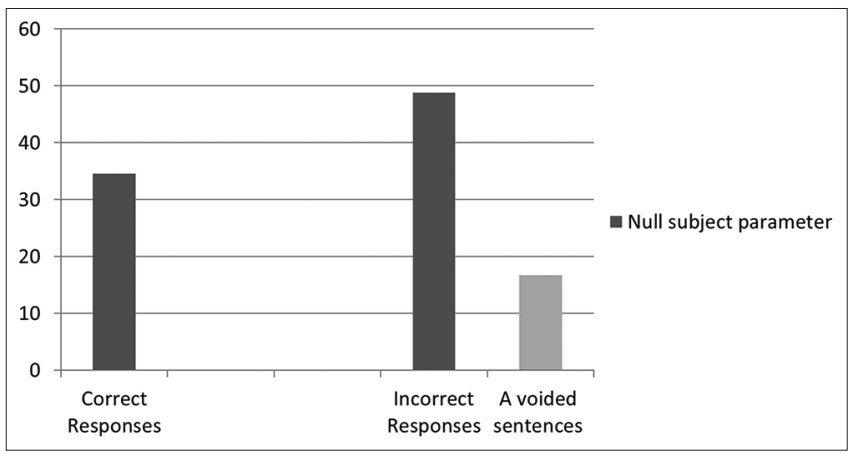

Figure 3. The frequency of resetting the null-subject parameter on the production level: Correction task

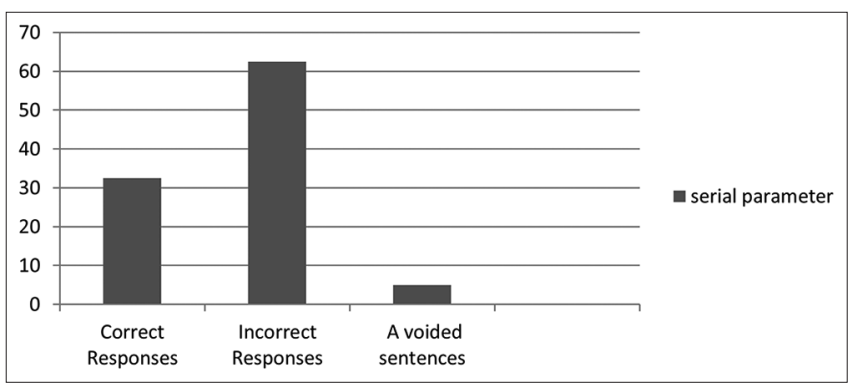

Figure 4. The frequency of resetting the serial parameter on the recognition level

head-directionality parameter exhibited the same results. That is, students correctly changed the sentences into their suitable forms. For example, a sentence such as 'The very kitten small jumped at the big dog' is correctly changed into 'The very small kitten jumped at the big dog' where the head adjective 'small' precedes its complement ' kitten'. The fol-

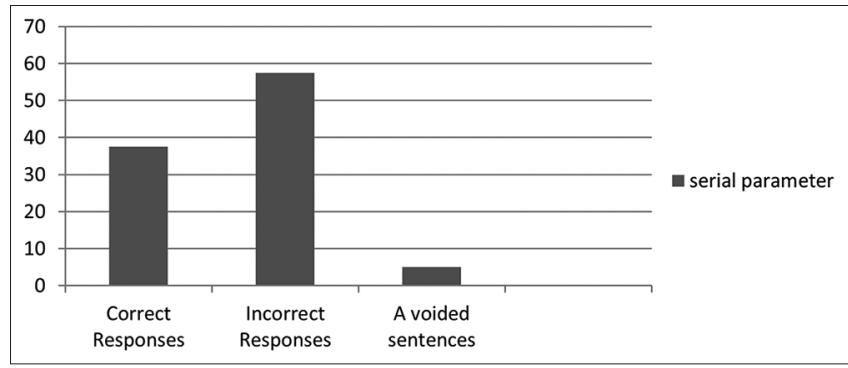

Figure 5. The Frequency of Resetting the Serial Parameter on Production Level: Translation Task

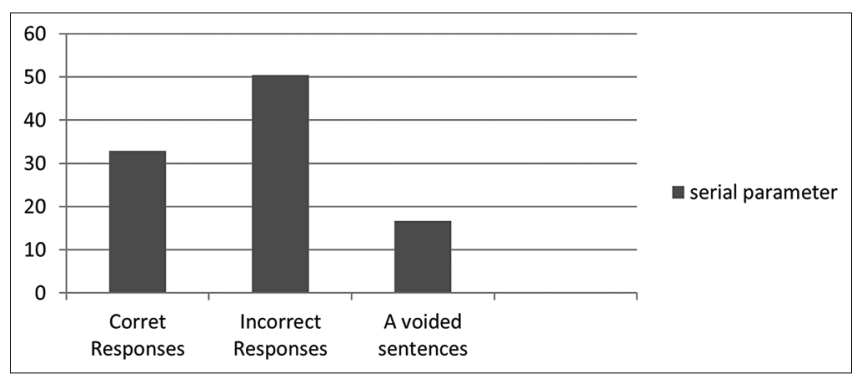

Figure 6. The Frequency of Resetting the Serial Parameter on the Production Level : Correction Task.

lowing Table 9 and Figure 9 show students' behaviour on the production level: correction task.

\section{CONCLUSIONS}

Based on the analysis of the data and the results thereof, the study has come up with the following conclusions:

1- Iraqi EFL $4^{\text {th }}$ Year college students were successful in resetting the Head-parameter. 
Table 8. The frequency of resetting the head-parameter on the production level: translation task.

\begin{tabular}{|c|c|c|c|c|c|}
\hline \multicolumn{2}{|c|}{ Correct responses } & \multicolumn{2}{|c|}{ Incorrect responses } & \multicolumn{2}{|c|}{ Avoided sentences } \\
\hline Frequency & Percentage & Frequency & Percentage & Frequency & Percentage \\
\hline 175 & $72.91 \%$ & 53 & $22.08 \%$ & 12 & $5 \%$ \\
\hline
\end{tabular}

Table 9. The frequency of resetting the head-parameter on the production level: correction task

\begin{tabular}{|c|c|c|c|c|c|}
\hline \multicolumn{2}{|c|}{ Correct responses } & \multicolumn{2}{|c|}{ Incorrect responses } & \multicolumn{2}{|c|}{ Avoided sentences } \\
\hline Frequency & Percentage & Frequency & Percentage & Frequency & Percentage \\
\hline 143 & $59.58 \%$ & 57 & $23.75 \%$ & 40 & $16.66 \%$ \\
\hline
\end{tabular}

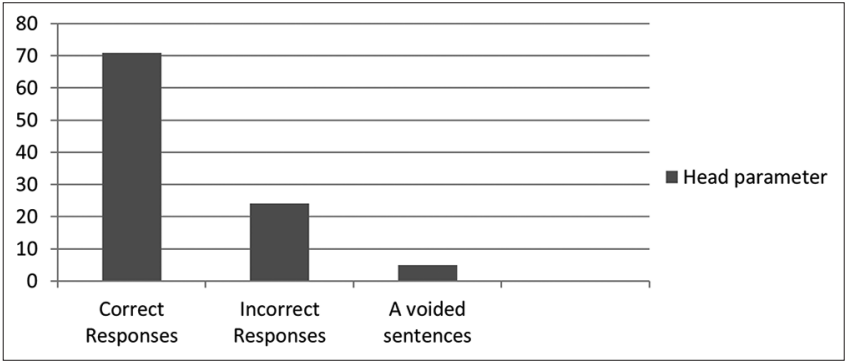

Figure 7. The frequency of resetting the head-parameter on the recognition level

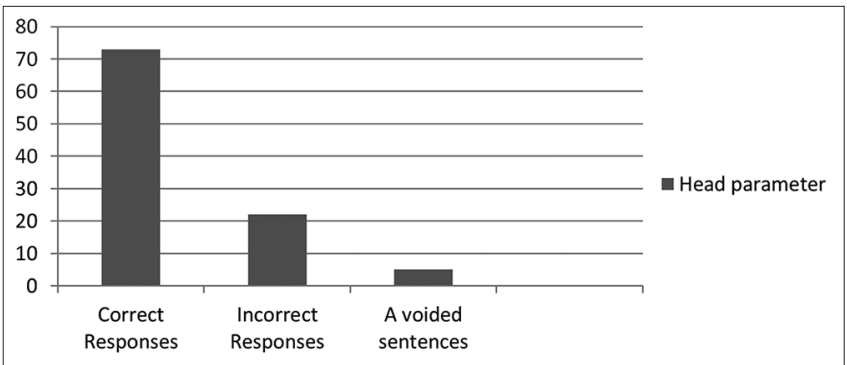

Figure 8. The frequency of resetting the head-parameter on the production level: translation task

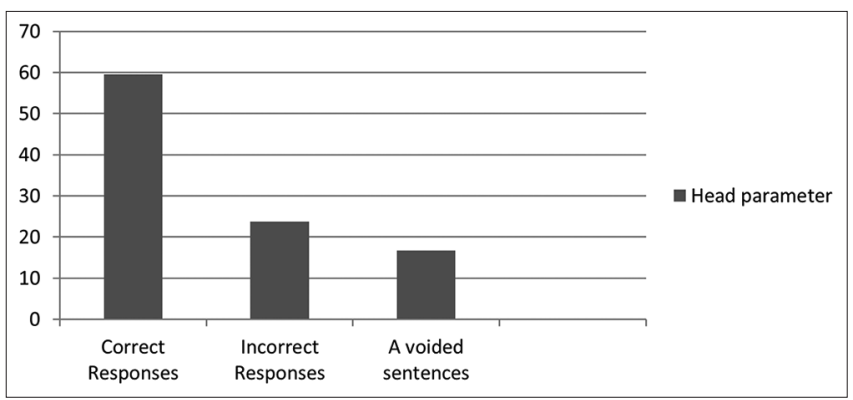

Figure 9. The frequency of resetting the head-parameter on the production level: Correction task

2- Iraqi EFL $4^{\text {th }}$ Year college students were unable to reset the serial parameter into its right settings in English.

3- As to the null-subject parameter, the Iraqi students fluctuated between Arabic and English parametric settings and could not acquire the English parameter setting fully.

4- The study proved that L2 learners' initial state was indeed the L1 grammar in the sense that Iraqi students have transferred the parametric values of Arabic into English when confronted with sentences that are ungrammatical in their native language. That is, they never resorted to strange structures when in the process of L2 learning. In other words, they draw on the knowledge of their native language when encountering English sentences set at a value different from their first language value.

5- The study ensures that L2 grammar is constrained by UG in much the same way as the L1 grammar in the sense that the students return to the parametric values available by UG and never use structures not found in human natural languages. That is, the grammar constructed at each stage of linguistics development is UG constrained.

6- The successful resetting of the Wh-parameter and the Head-parameter revealed that parameters resetting can occur in the process of second language learning with the subjects being exposed to extensive input data from the $\mathrm{L} 2$ to force the resetting.

7- Failure to reset some parameters like serial parameter is due to a negative transfer from Arabic to English in the sense that they allow Arabic parameter settings instead of the English ones.

8- The inconsistency of students' responses as adhering to values of both languages in handling the different tasks of the same parameter may be ascribed to their unawareness of the type of parametric variation between Arabic and English. As well, the lack of more positive data may work hand in hand with their unawareness as a hindrance for the full ability of resetting.

9- GJTs used in this study make a reliable measure of EFL learners' knowledge about parameters resetting. It measures students' implicit knowledge in a precise way, thus other researchers can depend on such a kind of test in SLA research.

\section{REFERENCES}

As'ad, M. (2002). Nahwu-llughati-l-Arabiyah: Kitaabun fi Qwaa'idil-Nahwu waa-Sarf "Grammar of Arabic: A Book in the Rules of Syntax and Morphology". Beirut: Al-Maktabatul-Misriyah.

Chomsky, N. (1981). Lectures on Government and Binding. Dordrecht: Foris

Cook, V., \& Newson, M. (1996). Chomsky's Universal Grammar.USA: Blackwell Publisher.

Freidin, R. (2007). Generative Grammar: Theory and its History. London: Routledge. 
Harvie, D. (2011). Null Subjects in English. London: Routledge. Iwasaki, Sh. \& Preeya, I. (2005). A Reference Grammar of Thai. Cambridge: Cambridge University Press.

Khalaf, A. (1994). Nahwul-Lughatil-Arabiyah "Grammar of Arabic". Cairo: Maktabatul-Aadaab.

Kreidler, Ch.2001). Phonology: Critical Concepts in Linguistics. London: Routledge.

Radford, A. (2004). Minimalist Syntax. Cambridge: Cam- bridge University Press.

Stewart, Th. (2013). The Serial Verb Construction Parameter. London: Routledge.

al-Taahir, K. (2002). Mabaadi' Duroosil-Arabiayh "Principles of Lessons on Arabic”. Cairo: ad-Daarul-Misriyah al-Lubnaniyah

White, L. (2003). Second Language Acquisition and Universal Grammar. Cambridge: Cambridge University Press.

\section{APPENDIX I: GRAMMATICALITY JUDGMENT TASK}

\section{Part One: Tick the correct sentences}

1- Suddenly, jumped from the window.

2- Many people started saying that they saw a ghost.

3- The gold is very precious.

4- What is going to become of us now?

5- Cats are pretty animals.

6- Marry wants to buy white flowers beautiful.

7- Bill entered the room skipped.

8- Bill plays football every Friday.

9- John bought a new beautiful house.

10 -Ali speaks what languages?

11 - I like food and I eat quite a lot.

12 - Bill an apple eats.

13 - Studied hard together.

14 - The tigers do not normally attack people.

15 - What are you doing?

16 - We camped by the rock.

17 - They heard her screamed.

18 - The student won the prize.

19 - I usually have a cup of tea with a little milk and no sugar.

20 - You said what?

\section{Part Two: Translate the following sentences into English}

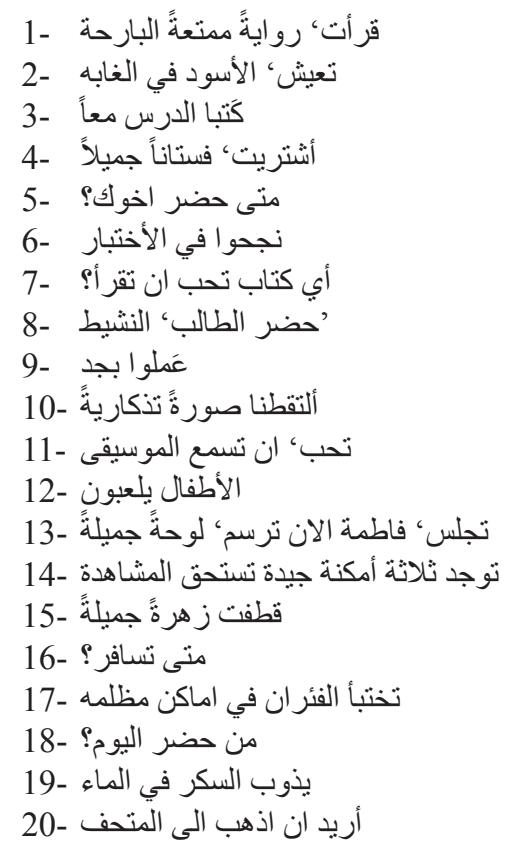




\section{Part Three: Correct the following sentences}

1- The sugar is sweet.

2- The dogs bite.

3- Mary liked which dress?

4- Each morning, eats breakfast at eight o'clock.

5- You would like which one?

6- The government encourages people stop smoking.

7- Muna an elephant drew.

8- He watched her played tennis.

9- I watched such a movie delightful.

10 - Sometimes, forget my phone at the office.

11 - The very kitten small jumped at the big dog.

12 - book is on the kitchen table.

13 - Your house is where?

14 - Seldom see John.

15 - The jacket did not fit I took it back to the store.

16 - Ben is an baby adorable.

17 -The water is good for health.

18 - You did brush your teeth when?

19 - went to the hospital.

20 - John wants sees a movie. 